\title{
PERI-IMPLANT MARGINAL BONE LOSS AND ORAL HEALTH-RELATED QUALITY OF LIFE IN PATIENTS TREATED BY MINI-IMPLANT-RETAINED MANDIBULAR OVERDENTURES WITH DIFFERENT OCCLUSAL SCHEMES (LINGUALIZED, MONOPLANE AND BILATERAL BALANCED): A RANDOMIZED CLINICAL TRIAL
}

\author{
Iman Adel El-Asfahani* and Eman Helal ${ }^{* *}$
}

\begin{abstract}
Purpose: To evaluate the peri-implant marginal bone loss and oral health-related quality of life in patients receiving mini-implant-retained mandibular overdentures with different occlusal schemes.

Materials and methods: Twenty-one completely edentulous patients were selected. All patients received complete dentures before the surgical procedures, The patients were randomly divided into three groups according to the occlusal scheme. Group I: complete dentures with lingualized occlusal scheme, Group II : complete dentures with Monoplane occlusal scheme, Group III : complete dentures with bilateral balanced occlusal scheme. Four mini implants were inserted and loaded in each patient in mandible intraforminally. The peri-implant marginal bone loss and oral health-related Quality of Life were evaluated at implant loading (baseline or zero month), six and twelve months after implant loading .

Results: No significant difference in the peri-implant marginal bone loss was found between Group I, II and III in the 0-6 follow-up period, while at the 0-12 follow-up period significant difference was found. No significant difference was obtained between total OHIP-EDENT scores in the three groups at baseline and 6-months follow up visits, while at the 12-months follow up visit, significant difference was found .

Conclusion: Within the limitations of this study, it can be concluded that in mini-implant retained mandibular overdentures, lingualized and monoplane occlusal schemes may provide better results in the peri-implant marginal bone loss aspect compared to bilateral balanced occlusal scheme. Furthermore, in patients' oral health-related Quality of Life aspect, lingualized occlusal scheme may be superior to monoplane and bilateral balanced occlusal schemes.
\end{abstract}

\footnotetext{
* Associate Professor, Removable Prosthodontics Department, Faculty of Dentistry Minia University, Egypt

** Researcher, Fixed \& Removable Prosthodontics Department, Oral \& Dental Research Institute, Cairo, Egypt
} 


\section{INTRODUCTION}

The quality of life for patients with edentulous mandibles is significantly improved by Implantretained overdentures when compared with conventional complete dentures ${ }^{1}$. Two standard diameter implants supporting a mandibular overdenture is considered the standard of care in edentulous patient's treatment as stated by consensus statements $^{2,3}$. Despite this fact, sometimes residual ridge resorption in edentulous patients and the execution of complicated surgical techniques makes insertion of standard-diameter implants challenging ${ }^{4}$ Hence, treatment with mini implants (with a reduced diameter less than $3 \mathrm{~mm}$ ), supported overdentures can provide a good alternative particularly in medically compromised patients as they offer fewer operative distress ${ }^{5}$. In some cases, it is not mandatory to open flaps, reducing morbidity throughout the postoperative phase ${ }^{6}$ which improved patient acceptance and satisfaction with mini-implant supported overdenture $^{7}$; it offers a favorable rehabilitation treatment option with comparable peri-implant shear stress as compared to standard diameter implants $^{8}$. This treatment modality enhances maximum occlusal force without the impairment of force distribution 9 . Owing to these attractive qualities, mini implants' usage has been a novel focus among implant studies ${ }^{10}$.

Various aspects can influence the occlusal load affecting the implants and the surrounding bone. Some are patient-linked such as bone quality, others are implant-linked such as Implant length, diameter, Design, distribution, angulation, position, and number ${ }^{11}$. It has been proved that the biomechanical characteristics of occlusal anatomy, configuration and design can drastically impact the longevity and success of dental implants. Actually, biomechanically controlled occlusal scheme that is in harmony with the rest of the stomatognathic system is has been considered by many researchers as a major factor in accomplishing long term clinical success of implant-supported prosthesis ${ }^{11,12,13}$. To choose an occlusal scheme for an implant supported overdenture critical in order to prevent overloading leading to mechanical complications for the implants; i.e. screw loosening and/fracture, fixture fracture... etc..$^{13,14}$. Evenly scattered occlusal contacts freedom in centric, centric occlusion with bilateral stability, anterior guidance whenever possible and smooth lateral movement without working or non-working side interferences are considered the basic philosophies of implant occlusion ${ }^{15}$. Favorable occlusal scheme (bilateral balanced, lingualized, group-function, monoplane, and mutually protected occlusion) in implant supported overdentures is debatable, there is no evidence to prove which occlusal scheme can fulfil all the success criteria and patients' demands ${ }^{16}$. Hence, researchers recommended specific schemes based on several criteria. A study endorsed bilateral balanced occlusion for mandibular implant overdentures as it provides proper force distribution, stability of the masticatory system ${ }^{17}$. It is superior in terms of masticatory efficiency and patient satisfaction as compared to monoplane occlusal scheme ${ }^{18}$. Though such scheme has been advocated as a perfect occlusal scheme by several studies, it might be problematic to be accomplished clinically and is time consuming ${ }^{19} \mathrm{Sev}-$ eral authors recommended that lingualized occlusion was the standard occlusal scheme to be used for implant overdentures as it provided a significantly reduced incidence of sore spots, higher masticatory efficiency and patient preference ${ }^{15,20,21}$. A study compared both occlusal schemes, lingualized occlusion showed favourable bone density and height changes compared to bilateral balanced occlusion ${ }^{22}$. Additionally, it is less time consuming and clinically easier to be accomplished than the bilateral balanced scheme ${ }^{23,24,25}$ Selecting Monoplane occlusion, especially in severely resorbed ridges, it has been reported that the stresses generated in the supporting tissues were lower with the 0 -degree teeth as compared to cusped teeth ${ }^{26}$ It was also reported that zero-degree denture teeth provided markedly lower pressure transmission to supporting structures as compared to cusped teeth. Therefore, it is 
recommended to use zero-degree teeth in cases with atrophied residual ridges ${ }^{27}$ In spite of this benefit, flat teeth in monoplane occlusion exhibit inferior esthetics and may cause further pain compared to lingualized occlusal forms. This may be because additional force is needed to pierce a food bolus with zero-degree teeth compared to cusped teeth ${ }^{19}$.

There is deficiency in scientific evidence concerning the occlusal scheme used with implant supported overdentures. Few studies were found in literature exploring the effect of using different occlusal schemes advocated in standard diameter or mini implant supported overdentures 20,26,27,28. Hence, this research was conducted as an attempt to investigate which occlusal scheme (bilateral balanced, lingualized or monoplane) can be more protective and preferred in mini implants supported mandibular overdentures.

\section{MATERIAL AND METHODS}

\section{Patient selection and grouping}

A total of twenty-one completely edentulous patients (10 females and 11 males, average age $63 \pm 11$ ) had been selected from the outpatient clinic, Faculty of Dentistry, Minia University. Cooperative Patients with clinically healthy mucosa and adequate bone height and width to accommodate $2.5 \mathrm{~mm}$ diameter and $10 \mathrm{~mm}$ height mini implants were included in the study. Patients free from any systemic condition that could affect osseointegration were also included. patients with poor oral hygiene, uncooperative patients, severe metabolism diseases, immunosuppressive or bisphosphonates therapy were excluded from the study. Heavy smokers or patients who received radiation to the head and neck region were also excluded. The edentulous ridges had been examined to exclude un- healthy, inflamed, flabby mucosa. The ridges with severe bony were excluded. Bone quantity and quality were checked by cone beam computed tomography (CBCT). The selected patients were informed about the nature of this research work. Only motivated patients participated in the study after signing a written consent.

For all patients, maxillary and mandibular complete dentures were constructed before the surgical procedures, The patients were randomly allocated and categorized sequence, using Microsoft Excel software (Microsoft Excel 2003; Microsoft Corporation) following 1:1:1 ratio, into three equal groups according to the selected occlusal scheme.

Group I: patients recieved complete dentures with lingualized occlusal scheme,

Group II : patients received complete dentures with Monoplane scheme,

Group III : patients received complete dentures with bilateral balanced occlusal scheme.

Afterwards, each patient received four one piece mini-implants (Mini plus fixture (ball), Cowellmedi Co.,Ltd.48 Hakgam-daero 221beon-gl, Busan, Republic of Korea) placed in the inter-foraminal edentulous ridge space.

\section{Prosthetic and surgical phases}

The complete dentures were constructed following the conventional denture fabrication methods. Upper and lower alginate (Cavex Holland B.V., P.O.Box 852-2006 R W Harrlem, Holland) impressions had been made to obtain stone (semiadjustable articulator Hanau Engineering co-inc Buffalo,N.Y) diagnostic casts. on which upper and lower acrylic resin Acrylic special tray Pekatray, Dentsply, USA. special trays were constructed. green stick compound green stick compound, Perfection, Italy was used for border molding of special trays. Using zinc oxide and eugenol Cavex Outline, Cavex Holland BV, Netherland, secondary impressions were done. Boxing and pouring of the impressions with dental stone to obtain secondary casts to construct trial denture bases on them. A maxillary face bow record was done to mount the upper cast on a semi-adjustable articulator ((HANAU, Wide; Whip Mix Corporation, 
Farmington Ave, Louisville, KY, USA). Centric relation record was taken following the wax wafer technique to mount the lower cast. Setting up of artificial teeth was done as follows:

In group I patients, setting-up of artificial teeth was done using cross linked modified acrylic resin teeth abiding by the rules of the lingualized occlusion scheme. The mandibular posterior teeth, lingual cusps of were positioned medial to a line drawn from the tip of the canine to the center of the retromolar pad. Widening of the central fossae of the Mandibular posterior teeth was done. The maxillary functional palatal cusps of the posterior teeth were set up to occlude in the widened central fossae of the mandibular posterior teeth. Grinding of the interlocking occlusal transverse ridges was done. The maxillary buccal cusps of the posterior teeth were ground to remove any contact between buccal cusps in eccentric and centric relations. Balanced contacts in protrusive movements occurred between palatal maxillary cusps and mandibular posterior teeth. Contact occurred only on the working side between maxillary palatal cusps and mandibular posterior teeth during lateral excursion. At the same time, palatal maxillary cusps contacted the lingual inclines of the buccal mandibular cusps on balancing side (Fig 1-a).

For group II artificial teeth were set up using non- anatomic teeth with flattened occlusal surfaces and reduced cuspal inclination according to the monoplane occlusal scheme. Teeth were set up to be parallel to the denture foundation plane anteroposteriorly. The mandibular posterior teeth posterior limit was the area where the mandibular ridge starts to curve upward. Additionally, teeth were situated flat without lateral or medial inclination. The mandibular second molar was set up out of occlusion directing the forces to the premolar-molar area. No overlap was done between upper and lower anterior teeth (Fig 1-b).

For group III, setting up of artificial teeth was performed utilizing semi-anatomic cross linked acrylic teeth following the bilateral balanced occlusal scheme. In centric and eccentric positions, artificial teeth were set up to have simultaneous contacts between opposing on both sides of the dental arches. The palatal functional cusps of the maxillary posterior teeth were set up to occlude with the central fossae of mandibular posterior teeth. Maxillary buccal cusps also contacted the buccal inclines of the mandibular buccal cusps. In lateral and protrusive excursions, buccal and lingual cusps were set up to be in articulation and function (Fig 1-c).

During waxing up, labial and lingual flanges of the mandibular trial denture in the three groups patients, were thickened at the inter-foraminal area i.e., between the first two premolars. Try in of the upper and lower trial dentures was done in the patient's mouth. Afterwards, they were flasked, processed, finished, and polished conventionally. Delivery of the finished dentures to the patients and all necessary occlusal adjustments were carried out intraorally and in the laboratory.

A $3 \mathrm{~d}$ printed surgical stent was constructed for each patient through the data attained from CBCT. Patients wearing their mandibular dentures with radiopaque markers, at the implants' planned sites, were scanned using the CBCT machine (SOREDEX.Nalikelantie 160, Tuusula. P.O.Box 148, FI-04301 Tuusula. Finland). Afterwards, the mandibular denture with the radiopaque markers was scanned with CBCT. The Images of the CBCT were sent to a viewing software to examine the bone quality and quantity at the implants' sites and then fabrication of the guide was executed. They were constructed from clear acrylic resin (Acrostone dental factory, Egypt) having four metal sleeves, at the predetermined implants' positions, fitting precisely the removable sleeves offered by the manufacturer. To place the anchor pins for the guide fixation, three cylinders (one mid-labial and two laterals) were provided in each guide 


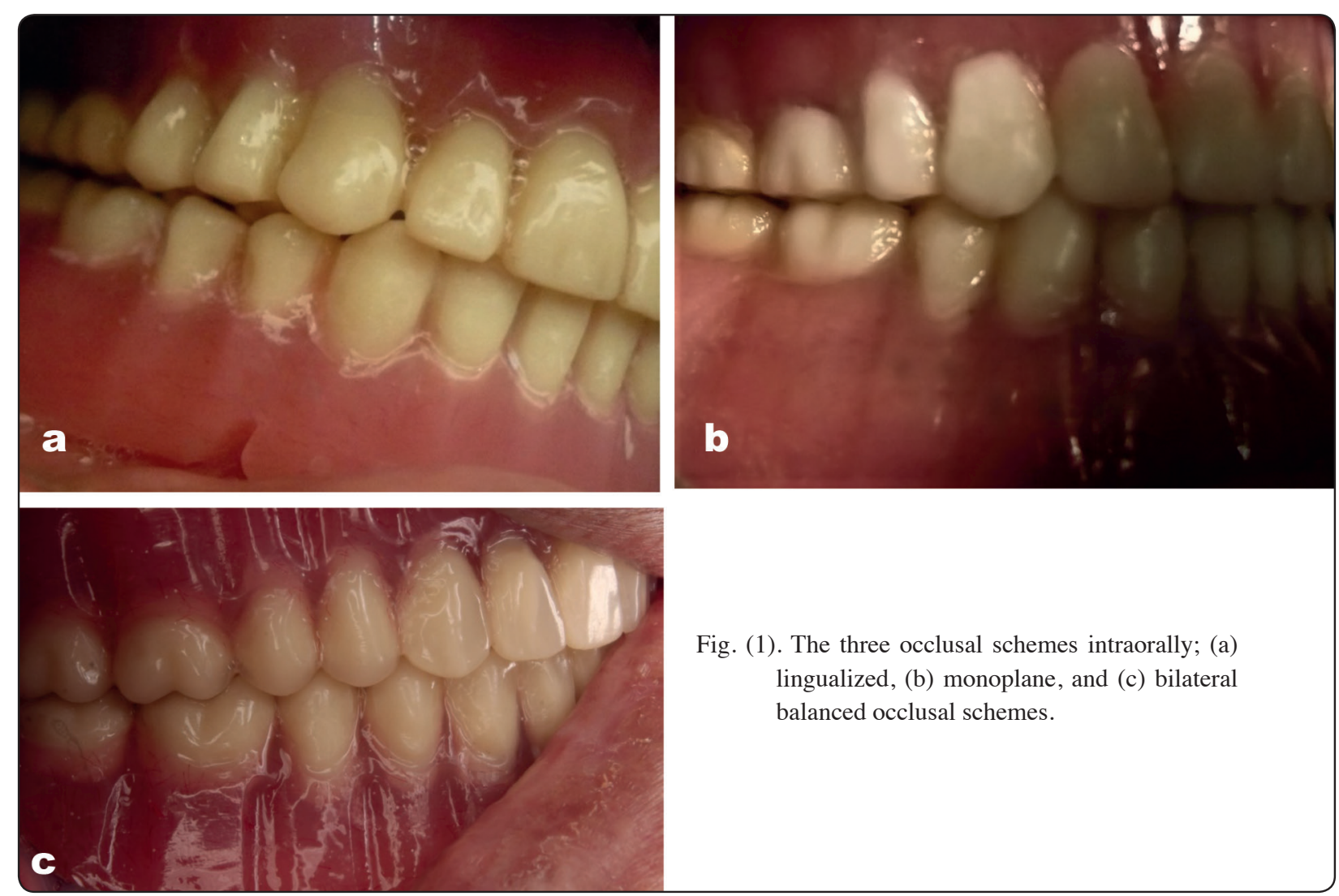

Each patient was prepared for the operation by prescribing an umbrella of antibiotics as an infection control measure 24 hours prior to the surgery and to be continued for 1 week . Non-steroidal antiinflammatory drug and chlorohexidine mouthwash were prescribed too. Their alveolar ridges were anesthetized using mental nerve block for both sides and ring infiltration anesthesia was added at the site to the surgical area. The surgical stent was inserted intraorally. Through the guides' supplied lateral cylinders, holes were drilled in the mandible to get the anchor pins to secure the guide in place. The surgical technique followed was flapless. four marks were created using the pilot drill guided by the stent in the planned mini-implant sites in the mandible. Following the removal of the surgical stent from the patient's mouth was done, a $2.0 \mathrm{~mm}$ surgical drill with plentiful irrigation of saline was utilized to prepare the 4 osteotomy sites in a vertical direction. Paralleling tool was used to ensure
Parallelism among the osteotomies. Removal of one mini implant (10mm length and $2.5 \mathrm{~mm}$ diameter) from the sterile packing utilizing the manual driver then inserted in the osteotomy sites and fastened until slight resistance was felt. Next, a ratchet was employed used to finally thread the implant full length with its head projecting above the mucosa. Implant insertion was done under ample irrigation. The same was done for the rest of the three mini implants. Fig. 2. All previously mentioned drugs were continued by the patients for following three days in addition to the strict oral hygiene procedures.

One week following implant insertion, patients were recalled for pick-up procedures, early implant loading and dentures insertion. Mini implants were attached to their corresponding metal housings. Blocking out the undercuts underneath the metal housings was done using glass ionomer cement (Medicem, Promedica dental material $\mathrm{GmbH}$, Germany). The area opposite to the metal housings 


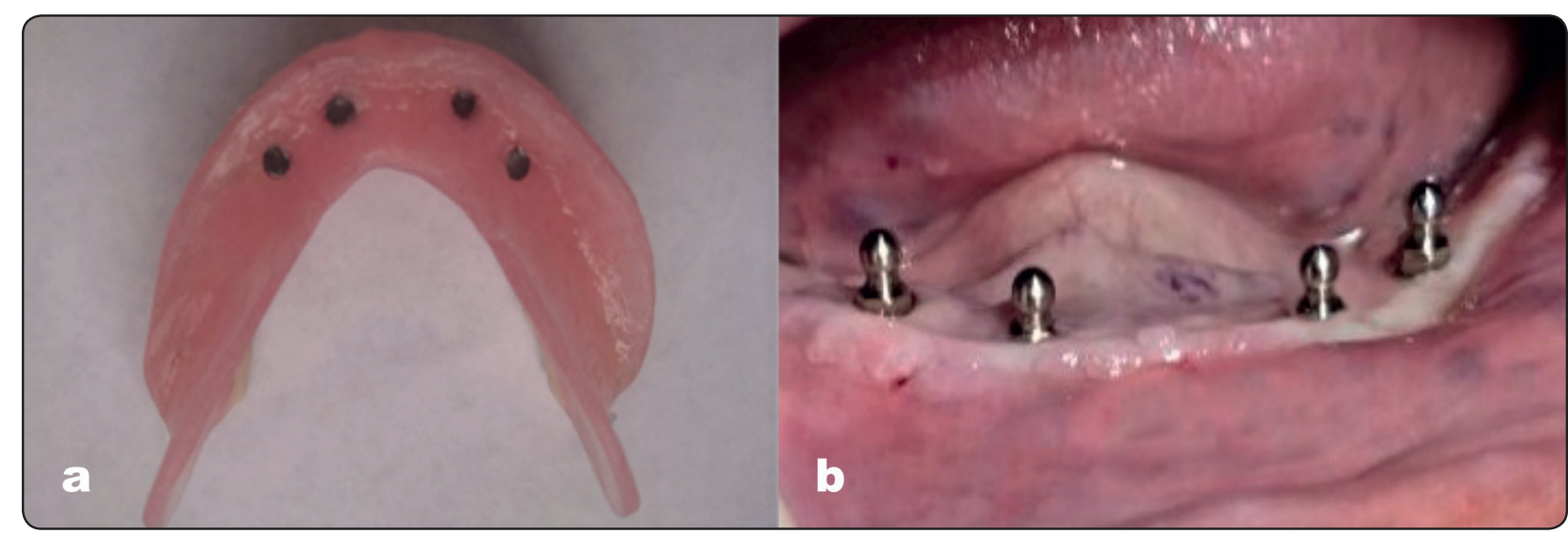

Fig. (2) (a) The overdenture fitting surface with the four metal housings, (b) the four mini implants intraorally.

were marked on the mandibular overdenture intaglio surface. Sufficient relief to the intaglio at those areas was made till seating of dentures in place with no rocking. For escaping of excess pick up material lingual escape holes were made. Cold cured acrylic resin (Acrostone, Egypt) was added to the relieved areas in the denture intaglio surface. The mandibular denture was reseated in place while asking the patient to close in centric position. After complete setting, the mandibular overdenture was removed from the mouth holding the nylon caps and metal housings attached to its intaglio surface .

\section{Radiographic evaluation}

Radiographic evaluation to assess the peri-implant marginal bone loss was measured after six and twelve months after implant loading in the patients of the three groups. The measurements of peri-implant marginal bone height mesial and distal to the mini-implants were assessed at implant loading (baseline or zero month), six and twelve months after implant loading by periapical radiographs carried out with standardized long cone paralleling technique. A Rinn periapical film holder (XCP Extention Cone Paralleling, DENTSPLY Rinn Corporation, USA) was utilized to get the radiographs, The x-ray tube was mounted by a long cone. Rinn technique was followed in every visit by means of the XCP instrument for extension cone paralleling technique and a phosphorus $\mathrm{X}$-ray plate was utilized to receive the image. Duplication of the patient's denture into clear acrylic stent to be employed in the follow up radiographs was done. Cold cure acrylic resin was used to attach the bite blocks of the Rinn $\mathrm{XCP}$ attached to the acrylic stent. Hence offering a reproducible and steady positioning of the phosphorus x-ray plate in every follow-up visit. All the films were exposed using the same $\mathrm{x}$-ray machine (Fona $\mathrm{XDC}$, Fona, Assago, Italy) at 8 milliamperes and 70 kilovolts for 0.6 seconds with a focal film distance of $35 \mathrm{~cm}$. the image data was read by a scanner which scanned the plate to form a digital image. The previously mentioned exposure parameters were fixed for all the patients in the follow-up visits for standardization of radiographs. Image display was viewed on the computer screen then saved to be analyzed by a Viewer software (Romexis Viewer software, Planmeca, Helsinki, Finland) to get the linear measurements. For Calibration, as an additional standardization technique for the measurements, and to avoid any human or procedural error or any distortion; the visible radiographic implant length of each implant was measured on each image and compared to the actual known length of the implant $(10 \mathrm{~mm})$. On the images imported to the software, a horizontal line was drawn tangential to the implant apex and perpendicular to its long axis. Next, two lines were drawn tangential to the implant mesial and distal surfaces starting from the first bone to implant contact extending to the horizontal line. 


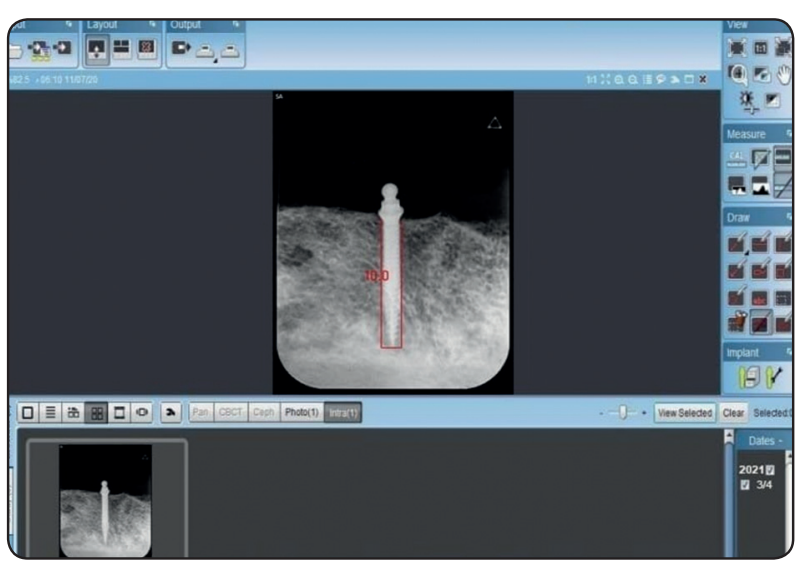

Fig. (3) Peri-implant marginal bone loss measurements

Linear measurements were obtained by calculation of the radiographic length of the individual implant, length of mesial and distal peri-implant marginal bone height fig. 3 . The images were evaluated by a calibrated clinician blinded by the nature of the study. Peri-implant marginal bone loss was calculated by subtracting follow-up visits peri-implant marginal bone height values from the baseline (zero month) peri-implant marginal bone height values.

\section{Oral health-related quality of life evaluation}

Oral Health-related Quality of Life (OHQoL) was evaluated by nineteen-question multiple-item questionnaire called OHIP-EDENT at baseline, 6and 12-months following implant loading. It was translated to Arabic and read to the patients seven domains: functional limitation, physical disability, physical pain, psychological discomfort, handicap , social disability, and psychological disability. Each question provides a choice of five answers, and each is given a score ( $0=$ never; $1=$ seldom; 2 = fairly often; 3 = often; 4 = very often). It ranges from 0 to 76 . The total score was calculated by adding the answers to all the questions The lowest score showed an acceptable perception of an individual's oral situation, and therefore better satisfaction and quality of life ${ }^{29}$. The linear measurements of the peri-implant marginal bone loss and OHIP-EDENT scores in each group were calculated, tabulated, and statistically analyzed.

\section{RESULTS}

Each patient in this study received a four miniimplant retained overdenture. All implants showed successful osseointegration (100\% survival rate) at the 6 months follow-up visit. All patients in this study were satisfied with their dentures. One patient from group II (monoplane occlusion) refused to continue in this study at the 12 months follow up visit as she used to come from a far Egyptian government.

\section{Peri-implant Marginal bone loss}

During the follow-up periods, the peri-implant marginal bone loss was evaluated at the mesial and distal of the implants in each group at the different follow up patient visits. Generally, there was a gradual and slight increase in the values of peri-implant marginal bone loss around the mini implants except one implant in Group I (lingualized occlusion) that showed an increase in bone height on the distal side instead of bone loss eventually, the mean of the mesial and distal peri-implant marginal bone loss around each implant was calculated. For comparing the mesial and distal surfaces peri-implant marginal bone loss around each implant, a paired t- test was done. There was no statistically significant difference between the two surfaces, therefore the mean of the two surfaces was calculated used for the statistical analysis. Finally, the mean peri-implant marginal bone loss for mini implants in each group was calculated.

The mean \pm standard deviation of the periimplant marginal bone loss in group I, II and III in the first follow up (0-6 months) period was $0.45 \pm$ $0.02 \mathrm{~mm}, 0.42 \pm 0.06 \mathrm{~mm}$, and $0.48 \pm 0.03 \mathrm{~mm}$ respectively. The mean peri-implant marginal bone loss in group I, II and III in the second follow up (012 months) period was $0.49 \pm 0.04 \mathrm{~mm}, 0.51 \pm 0.05$ $\mathrm{mm}$, and $0.96 \pm 0.13 \mathrm{~mm}$ respectively. To evaluate the effect of time on the peri-implant marginal bone loss at the two follow up periods in each group separately a paired t-test was done. No significant difference was found between the peri-implant 
marginal bone loss in the first and the second follow up periods in group I and II individually ( $p>0.05$ ). On the contrary, a significant difference between the peri-implant marginal bone loss in the first and the second follow up periods in group III compared to each other $(\mathrm{p}<0.05)$.

To evaluate the effect of occlusal scheme used in each group of patients on the peri-implant marginal bone loss, a multivariate ANOVA test was conducted. Non-significant difference in the periimplant marginal bone loss was found between Group I, II and III in the first follow up(0-6 months) period ( $p>0.05)$. On the other hand, a significant difference was found between Group I, II and III in the second follow up ( $0-12$ months $)$ period $(\mathrm{p}<0.05)$. table (1) and fig. 4. Consequently, ANOVA test was to compare the peri-implant marginal bone loss of in the second (0-12 months) follow up period in each two groups together. No significant difference in the peri-implant marginal bone loss was found between Group I and II in the second (0-12 months) follow up period $(\mathrm{p}>0.05)$. However, a significant difference in the peri-implant marginal bone loss was found between Group I and III in the second (0-12 months) follow up period $(\mathrm{p}<0.05)$. Also, there was a significant difference in the peri-implant marginal bone loss was found between Group II and III in the second (0-12 months) follow up period $(\mathrm{p}<0.05)$.

TABLE (1) The mean peri-implant marginal bone loss (in $\mathrm{mm}$ ) and standard deviation(SD) in the three groups at 1 st (0-6) and 2nd (0-12) follow up periods

\begin{tabular}{|c|c|c|c|}
\hline Follow up period & $\begin{array}{l}1^{\text {st }}(0-6 \text { months }) \text { follow-up period } \\
\text { Mean } \pm \text { SD mm }\end{array}$ & $\begin{array}{l}2^{\text {nd }}(0-12 \text { months }) \text { follow-up period } \\
\text { Mean } \pm \text { SD mm }\end{array}$ & $\begin{array}{c}\text { p-value of paired } \\
\text { t-test }\end{array}$ \\
\hline $\begin{array}{c}\text { Group I } \\
\text { Lingualized occlusion }\end{array}$ & $0.45 \pm 0.02 \mathrm{~mm}$ & $0.49 \pm 0.04 \mathrm{~mm}$ & 0.189281997 \\
\hline $\begin{array}{c}\text { Group II } \\
\text { Mono-plane occlusion }\end{array}$ & $0.42 \pm 0.06 \mathrm{~mm}$ & $0.51 \pm 0.05 \mathrm{~mm}$ & 0.121721524 \\
\hline $\begin{array}{l}\text { Group III } \\
\text { Bilateral balanced }\end{array}$ & $0.48 \pm 0.03 \mathrm{~mm}$ & $0.96 \pm 0.13 \mathrm{~mm}$ & $0.000049 *$ \\
\hline $\begin{array}{l}\text { P-value of } \\
\text { multivariate ANOVA test }\end{array}$ & 0.070 & $0.000024 *$ & \\
\hline
\end{tabular}

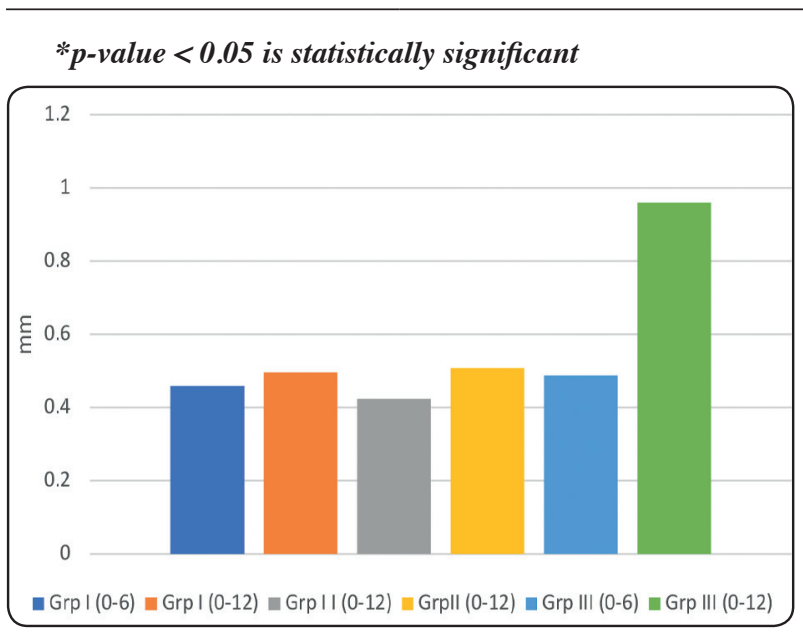

Fig. (4) The mean peri-implant marginal bone loss in group I, IIand III at the 1 st and 2 nd follow up periods

\section{Oral health-related quality of life}

All patients expressed general satisfaction with their implant retained overdentures. The mean \pm standard deviation of total OHIP-EDENT scores for Group I at the baseline, 6 and 12 month follow up visits was $66.28 \pm 20.33,24.43 \pm 12.16$ and $8.28 \pm 3.99$ respectively. The mean \pm standard deviation of total OHIP-EDENT scores for Group II at the baseline, 6 and 12 month follow up visits was $67.71 \pm 17.48,27.28 \pm 7.99$ and $15.57 \pm 2.99$ respectively. The mean \pm standard deviation of total OHIP-EDENT scores for Group III at the baseline, 
6 and 12 month follow up visits was $66.28 \pm 17.07$, $27.72 \pm 11.99$ and $15.28 \pm 7.13$ respectively. A Kruskal Wallis test was done to evaluate the effect of time on the OHIP-EDENT total scores in each group separately. All groups showed significant decrease in the total OHIP-EDENT scores between the baseline, 6- and 12-months follow up visits respectively $(\mathrm{p}<0.05)$. This denoted an improved patient's oral health-related Quality of Life in the three occlusal schemes groups. To evaluate the effect of occlusal scheme on patient's oral healthrelated Quality of Life, Kruskal Wallis test was. No significant difference was obtained between total OHIP-EDENT scores in the three groups at baseline and 6-months follow up visits ( $\mathrm{p}>0.05)$. On the other hand, a significant difference was found between the scores at the 12-months follow up visit $(\mathrm{p}<0.05)$ table (2) . Consequently, a Mann-Whitney test was done to compare the total OHIP-EDENT scores at 12-months follow up visit between each two groups together separately. A significant difference was attained between groups I scores compared to group II and III individually. On the contrary, no significant difference $(\mathrm{p}>0.05)$ was found between group II and III compared to each other.

A Kruskal-Wallis test was done to compare the scores of OHIP-EBENT questionnaire (at baseline,
6 and 12 months) in each Domain separately in group I, II and III table (3), fig.5. There was no significant difference between the scores of each domain in the three groups at the baseline and 6-months follow up visits ( $p>0.05)$. Additionally, no significant difference was found between the functional limitation, psychological disability, social disability and Handicap domains in the three groups at the 12- months follow visit $(p>0.05)$. However, a significant difference was found between the scores of the physical pain, psychological discomfort and physical disability domains in the three groups at the 12- months follow visit $(\mathrm{p}<0.05)$. Therefore, a Mann- Whitney test was done to compare the scores of these domains at 12-months follow up visit between each two groups together. In the physical pain domain, group III scores were significantly higher than group I and II individually $(\mathrm{p}<0.05)$. On the contrary, no significant difference was found between group I and II compared to each other $(\mathrm{p}>0.05)$. In the psychological discomfort and physical disability domains, the scores of group I were significantly lower than group II and III compared separately $(\mathrm{p}<0.05)$. On the other hand, no statistically significant difference was found between group II and III in the latter domains $(\mathrm{p}>0.05)$.

TABLE (2) Means and standard deviations of total OHIP-EDENT scores in group I, II and III at the different follow up visits

\begin{tabular}{|c|c|c|c|c|}
\hline $\begin{array}{l}\text { Follow up visit total OHIP-EDENT } \\
\text { score }\end{array}$ & Group I & Group II & Group III & p-value \\
\hline $\begin{array}{l}\text { Baseline (0 month) follow up visit score } \\
(\text { mean } \pm \text { SD) }\end{array}$ & $66.28 \pm 20.33$ & $67.71 \pm 17.48$ & $1.28 \pm 17.07$ & 1.357 \\
\hline $\begin{array}{l}6 \text { months follow up visit score } \\
(\text { mean } \pm \text { SD })\end{array}$ & $24.43 \pm 12.16$ & $27.28 \pm 7.99$ & $27.72 \pm 11.99$ & 0.758 \\
\hline $\begin{array}{l}12 \text { months follow up visit score } \\
(\text { mean } \pm \text { SD) }\end{array}$ & $8.28 \pm 3.99$ & $15.57 \pm 2.99$ & $15.28 \pm 7.13$ & $0.0000 *$ \\
\hline p-value & $0.0001 *$ & $0.003 *$ & \multicolumn{2}{|c|}{$0.000074 *$} \\
\hline
\end{tabular}

$* p$-value $<0.05$ is statistically significant 
TABLE (3) Means and standard deviations of OHIP-EDENT scores of each domain in group I, II and III at the different follow up visits

\begin{tabular}{|c|c|c|c|c|c|c|c|}
\hline \multicolumn{8}{|c|}{ OHIP- EDENT domains } \\
\hline $\begin{array}{l}\text { Scores at different } \\
\text { follow up visits } \\
\quad(\text { mean } \pm \text { SD })\end{array}$ & $\begin{array}{l}\text { Functional } \\
\text { limitation }\end{array}$ & $\begin{array}{l}\text { Physical } \\
\text { pain }\end{array}$ & $\begin{array}{l}\text { Psychological } \\
\text { discomfort }\end{array}$ & $\begin{array}{l}\text { Physical } \\
\text { disability }\end{array}$ & $\begin{array}{l}\text { Psychological } \\
\text { disability }\end{array}$ & $\begin{array}{c}\text { Social } \\
\text { disability }\end{array}$ & Handicap \\
\hline $\begin{array}{l}\text { Group I at baseline } \\
\text { (0 month) follow up visit }\end{array}$ & $10 \pm 0.82$ & $13.86 \pm 1.35$ & $6.43 \pm 1.90$ & $11.29 \pm 0.95$ & $6.86 \pm 1.57$ & $11.29 \pm 1.50$ & $6.57 \pm 1.81$ \\
\hline $\begin{array}{l}\text { Group II at baseline } \\
\text { ( } 0 \text { month) follow up visit }\end{array}$ & $10.57 \pm 0.79$ & $13.57 \pm 1.27$ & $6.86 \pm 1.46$ & $11.14 \pm 1.07$ & $7.14 \pm 1.46$ & $10.71 \pm 2.21$ & $7.71 \pm 0.49$ \\
\hline $\begin{array}{l}\text { Group III at baseline } \\
\text { (0 month) follow up visit }\end{array}$ & $9.71 \pm 0.95$ & $13.14 \pm 0.90$ & $7.00 \pm 1.41$ & $11.29 \pm 1.50$ & $7.14 \pm 1.46$ & $10.86 \pm 0.90$ & $7.14 \pm 1.07$ \\
\hline p-value & 1.785 & 0.456 & 0.089 & 0.671 & 1.254 & 0.782 & 1.546 \\
\hline $\begin{array}{l}\text { Group I at 6-months } \\
\text { follow up visit }\end{array}$ & $4.43 \pm 1.27$ & $6.43 \pm 1.27$ & $2.43 \pm 1.13$ & $2.57 \pm 0.98$ & $1.29 \pm 0.95$ & $4.57 \pm 1.51$ & $2.71 \pm 1.50$ \\
\hline $\begin{array}{l}\text { Group II at 6-months } \\
\text { follow up visit }\end{array}$ & $4.71 \pm 1.8$ & $6.00 \pm 1.53$ & $3.43 \pm 1.51$ & $3.71 \pm 1.25$ & $2.71 \pm 0.95$ & $3.86 \pm 1.77$ & $2.86 \pm 1.21$ \\
\hline $\begin{array}{l}\text { Group III at } 6 \text {-months } \\
\text { follow up visit }\end{array}$ & $5.29 \pm 2.06$ & $6.86 \pm 2.27$ & $2.86 \pm 1.46$ & $3.29 \pm 1.25$ & $2.14 \pm 1.86$ & $4.71 \pm 1.70$ & $2.57 \pm 1.40$ \\
\hline p-value & 0.478 & 1.764 & 0.652 & 0.075 & 1.528 & 0.342 & 0.296 \\
\hline $\begin{array}{l}\text { Group I at } 12 \text {-months } \\
\text { follow up visit }\end{array}$ & $1.57 \pm 1.13$ & $2.00 \pm 1.29$ & $0.57 \pm 0.53$ & $0.71 \pm 1.11$ & $1.29 \pm 1.25$ & $1.57 \pm 1.27$ & $0.57 \pm 0.79$ \\
\hline $\begin{array}{l}\text { Group II at } 12 \text {-months } \\
\text { follow up visit }\end{array}$ & $2.57 \pm 0.98$ & $2.14 \pm 1.35$ & $2.00 \pm 1.73$ & $2.86 \pm 1.35$ & $2.00 \pm 0.82$ & $2.43 \pm 0.79$ & $1.57 \pm 0.79$ \\
\hline $\begin{array}{l}\text { Group III at 12-months } \\
\text { follow up visit }\end{array}$ & $2.71 \pm 1.80$ & $4.14 \pm 1.68$ & $1.86 \pm 1.21$ & $2.00 \pm 1.15$ & $1.43 \pm 1.13$ & $2.14 \pm 1.68$ & $1.00 \pm 1.15$ \\
\hline p-value & 0.078 & $0.0001 *$ & $0.00038 *$ & $0.0000 *$ & 0.643 & 1.286 & 0.096 \\
\hline
\end{tabular}

\section{$*$ p-value $<0.05$ is statistically significant}

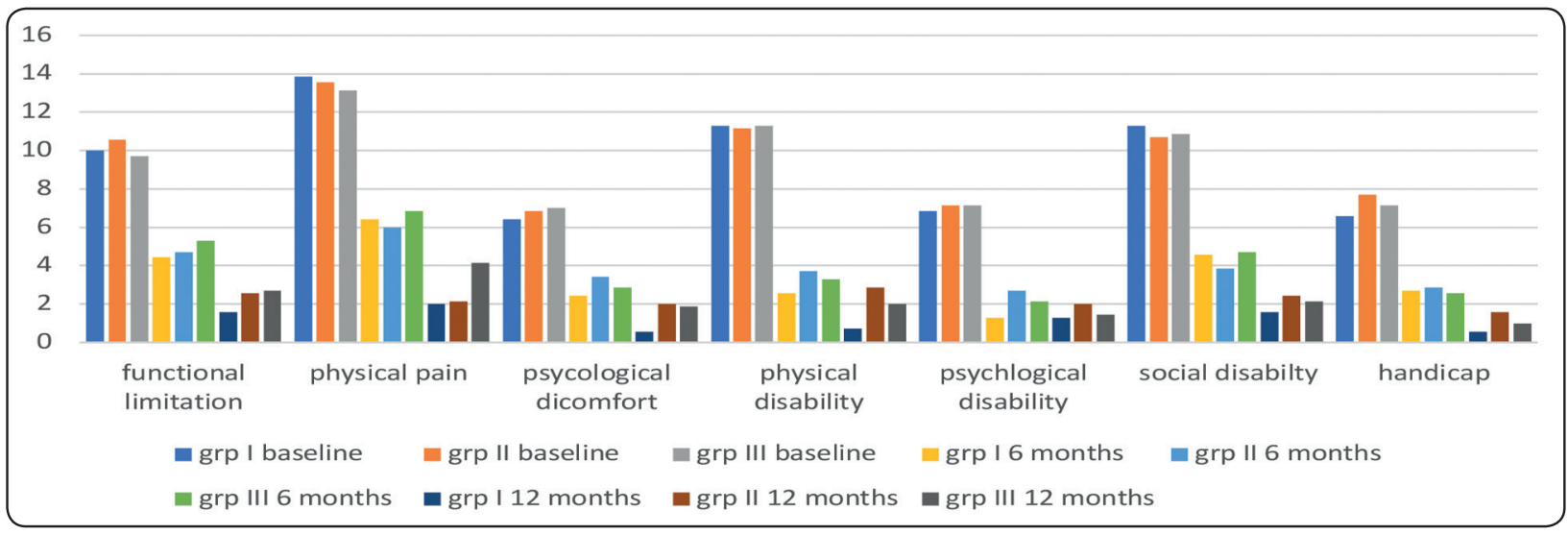

Fig. (5) The mean of OHIP-EDENT domains' scores at Different follow up visits (0, 6, 12 months) in groups I,II and III 


\section{DISCUSSION}

The usage of mini implant to support an overdenture has become increasingly accepted and advocated owing to their reduced diameter enabling practitioners to insert them in narrow alveolar ridges with less complex surgical techniques lowering postoperative morbidity, speeding up healing process and increasing patient's acceptance ${ }^{10}$. Recent guidelines support the insertion of four mini implants to support a mandibular overdenture ${ }^{30}$. Most research work is directed at standard diameter implants, there is relative knowledge insufficiency about clinical performance of mini implants, surrounding bone, esthetic expectations, patient's biting force and appropriate occlusal scheme. Recommendation of the implant supported overdentures occlusal schemes were mostly based on their use in conventional complete dentures. There is lack of evidence-based research on the effect of different occlusal schemes in implant supported overdentures.

It is mandatory that the clinician should be well acquainted with the different occlusal schemes used with an implant prosthesis to ensure its success. All the effort should be done to lower the overload, direct most of forces along the implant long axis and minimize off axial forces on implants throughout all mandibular movements ${ }^{31}$. This may be attributed to the absence of periodontal ligaments around implants which act as a shock absorber and proprioceptive motion feedback around natural teeth. Additionally, following osseointegration, any mechanical stresses further than the physical boundaries of supporting bone is suggested as the main cause of early crestal bone loss, screw loosening, prosthesis fracture, peri-implant tissues disease and implant failure ${ }^{32}$. Owing to the narrow diameter of mini implants, the implant displacement and profile are reduced. This causes an off-axial load 1.5-2.5 times the load imparted by a standard diameter implant on the surrounding bone ${ }^{33}$. Hence, over-load and subsequent failure should be avoided by controlling occlusal loads. Consequently, it is extremely crucial to choose an appropriate protective occlusal scheme that follows proper biomechanical principles where mini implants are secured from off-axial loads and eccentric forces are minimized ${ }^{28}$.

On loading an implant, stress is transmitted by the implant to the bone, and the maximum stress concentrates at the implant neck and its contact with bone ${ }^{34}$. Accordingly, the current study investigated the effect of different occlusal schemes (lingualized, monoplane and balanced) on peri-implant marginal bone loss. In all group bone loss did not exceed 1.5 $\mathrm{mm}$ which is the normal range of any successful implant through the first year ${ }^{35}$. This outcome agrees with the outcome of other study which investigated the peri-implant marginal bone loss around mandibular supported overdenture ${ }^{36}$.

The bilateral balanced occlusal scheme was chosen in this study as it has the benefit of high masticatory efficiency and stability. It was compared with the lingualized and monoplane to investigate their effect on peri-implant marginal bone loss. No significant difference was found in bone loss in the first follow up period (0-6 months) between the three groups . Unfortunately, a statistically significant unfavorable results of the bone loss regarding the bilateral balanced occlusion in the second follow up period (0-12 months) when compared to lingualized and monoplane occlusal schemes. This may be due to relatively increased number and location of occlusal contacts in bilateral balanced occlusion, which may have affected occlusal overload on implants, compared to lingualized occlusion where only lingual maxillary cusps are in contact with mandibular teeth central fossae in centric and eccentric movements. Accordingly, lingualized occlusion affords wide occlusal freedom which might aid in lowering the transmitted lateral forces to the implant. Moreover, an occlusal contact on buccal cusp may be an offset load while the implant is underneath the central fossa, considered as cantilever from the implant body. Also, angled buccal cusp incline may produce an angled load to the implant body ${ }^{37}$. In monoplane occlusion, the zero degrees inclination of cusps centralize the masticatory force and equilibrate the incline. Moreover, the use of cuspless teeth may lessen the 
pressure and eradicate the lateral stresses directed to the supporting structures than cusped teeth ${ }^{24}$. The results agree with three studies which recommended that lingualized occlusion as the standard occlusal scheme to be utilized in implant overdentures $15,28,38$ and in severe residual ridge resorption cases monoplane occlusion is indicated ${ }^{15}$.

Patients' quality of life is significantly affected by their satisfaction with their implant supported overdentures. Hence, the improvement in quality of life is a chief treatment objective for implantsupported overdentures ${ }^{39}$. the patient satisfaction has to be a dominant feature for the success and quality of treatment . Oral Health Impacted Profile (OHIP) is an internationally documented tool to evaluate the oral health-related quality of life of patients. The OHIP-EDENT is a shorter version of the OHIP which is proven to the most effective form of recognizing oral and prosthetic problems of edentulous patients ${ }^{40}$. All patients in this study were satisfied with their dentures and showed an improvement in the oral health-related Quality of Life which was obvious by the significant decrease in scores of the OHIP scores with time in all groups. This result is consistent with several studies which proved that oral health-related Quality of Life was improved with mini implant supported overdentures $^{10,41,42}$.

The total and domain scores a of OHIP-EDENT in the three groups were not statically significant difference during the study period except at the 12-months follow up, lingualized occlusal scheme total scores were significantly lower than monoplane and bilaterally balanced schemes compared separately. Additionally, lingualized occlusal scheme scores were significantly lower in the psychological discomfort and physical disability domains compared individually with monoplane and bilateral balanced occlusal schemes. No statistically significant difference was found between latter two groups domains. This may be attributed to placing the contact mainly on the lingual cusp in lingualized scheme in all mandibular movements may have led to increase in lever stability, directing forces central- ly lingual to the ridge, better masticatory efficiency compared to bilateral balanced occlusal scheme. In a systematic review comparing occlusal schemes in complete denture wearers stated that lingualized occlusion offered better quality of life/satisfaction or masticatory performance and muscle activity compared to bilateral balanced occlusion. Likewise, lingualized occlusion provided relatively natural appearance with semi-anatomic teeth, absence of deflective occlusal forces, direction the forces of mastication vertically to the supporting structures, better retention and comfort ${ }^{42,43}$. On comparing monoplane occlusal scheme with bilateral balanced occlusion, the former better results in the OHIP two domains may be attributed to the more rapid neuro muscular adaptation compared to bilateral balanced scheme.

The lingualized with semi anatomic teeth provided a significantly higher masticatory efficiency, better esthetics, and patient satisfaction than monoplane $^{23}$. This result was confirmed by two studies which compared different occlusal schemes on standard diameter implant supported overdentures ${ }^{20,43}$. At 12 months follow up visit, the scores of physical pain domain in the bilateral balanced occlusal scheme were significantly higher compared to lingualized and monoplane schemes scores. This domain is related to patient comfort especially during eating, this may be due to the greater need of alterations in chewing pattern for overdenture wearers leading to extending the period of patients' adaptation compared to the monoplane scheme and increase in lateral and protrusive grinding habits ${ }^{44}$. Additionally, it may be due to the superior stability provided by lingualized occlusal scheme compared to bilateral balanced one. Within the limitations of this study, it can be concluded that in mini-implant supported mandibular overdentures, lingualized and monoplane occlusal schemes may provide better results in the peri-implant marginal bone loss aspect compared to bilateral balanced occlusal scheme. Furthermore, in patients' oral health-related Quality of Life aspect, lingualized occlusal scheme may be superior to monoplane and bilateral balanced occlusal schemes. 


\section{REFERENCES}

1. Das KP, Jahangiri L, Katz RV. The first-choice standard of care for an edentulous mandible: a Delphi method survey of academic prosthodontists in the United States. J Am Dent Assoc. 2012; 143:881-9.

2. Feine JS, Carlsson GE, Awad MA, et al. The McGill consensus statement on overdentures: mandibular twoimplant overdentures as first choice standard of care for edentulous patients. Gerodont. 2002; 19(1):3-4.

3. Thomason JM, Feine J, Exley C, et al. Mandibular two implant supported overdentures as the first choice standard of care for edentulous patients: the York Consensus Statement. Br Dent J. 2009;207(4):185-186.

4. Ortega-Oller I, Suárez F, Galindo-Moreno P, TorrecillasMartínez L, Monje A, Catena A, et al. The influence of implant diameter on its survival: a meta-analysis based on prospective clinical trials. J Periodontol. 2014;4: 569-80.

5. Pihlstrom BL. Patient satisfaction with overdentures supported by mini-implants is comparable with overdentures supported by standard implants. J Ameri Dent Assoc. 2016; 147 (1): 64-72.

6. Ribeiro AB, Della Vecchia MP, Cunha TR, Sorgini DB, Dos Reis AC, Muglia VA, de Albuquerque RF, de Souza RF. Short-term post-operative pain and discomfort following insertion of mini-implants for retaining mandibular overdentures: a randomized controlled trial. J. Oral Rehabil. 2015; 42: 605-14.

7. Elsyad MA. Patient satisfaction and prosthetic aspects with mini-implants retained mandibular overdentures. A 5-year prospective study. Clin. Oral Implants Res. 2016; 27: 926-33.

8. Borges GA, Presotto AGC, Caldas RA, Pisani MX, Mesquita MF. Is one dental mini-implant biomechanically appropriate for the retention of a mandibular overdenture? A comparison with Morse taper and external hexagon platforms. J Prosthet Dent. 2021;125(3):491-499.

9. Kabbua P, Aunmeungtong W, Khongkhunthian P. Computerised occlusal analysis of mini-dental implantretained mandibular overdentures: A 1-year prospective clinical study. J Oral Rehabil. 2020; 47:757-65.

10. Vi S, Pham D, Du YM, Arora H, Tadakamadla, SK. MiniImplant-Retained Overdentures for the Rehabilitation of Completely Edentulous Maxillae: A Systematic Review and Meta-Analysis. Int. J. Environ. Res. Public Health. 2021;18: 4377-85.

11. Misch CE. Contemporary Implant Dentistry. 3rd ed. . St. Louis: Mosby Elsevier; 2008.
12. Adell R, Eriksson B, Lekholm U, Brånemark PI, Jemt T, Long-term follow-up study of osseointegrated implants in the treatment of totally edentulous jaws. Int J Oral Maxillofac Implants. 1990 Winter;5(4):347-59.

13. Kaukinen JA, Edge MJ, Lang BR. The influence of occlusal design on simulated masticatory forces transferred to implant-retained prostheses and supporting bone. J Prosthet Dent. 1996 Jul;76(1):50-5.

14. Schwarz M. Mechanical complications of dental implants. Clinical Oral Implants Res. 2000; 11: 156-158.

15. KimY,Oh TJ,Misch CE, Wang HL.Occlusal considerations in implant therapy: clinical guidelines with biomechanical rationale. Clin Oral Implants Res 2005; 16:26-35

16. Goldstein G, Goodacre C, Taylor T. Occlusal Schemes for Implant Restorations: Best Evidence Consensus Statement. J Prosthodont. 2021 Apr;30(S1):84-90.

17. Chapman RJ.Principles of occlusion for implant prostheses: guidelines for position, timing, and force of occlusal contacts. Quintessence Int 1989; 20:473-480.

18. Sutton AF, McCord JF. A randomized clinical trial comparing anatomic, lingualized, and zero-degree posterior occlusal forms for complete dentures. J Prosthet Dent. 2007;97(5):292-8.

19. Parr G, Ivanhoe J. Lingualized occlusion. An occlusion for all reasons. Dent. Clin. . 1996;40:103-12.

20. Khamis MM,Zaki HS, Rudy TE. A comparison of the effect of different occlusal forms in mandibular implant overdentures. J Prosthet Dent 1998; 79:422-29.

21. Wismeijer D, van Waas MA, Kalk W. Factors to consider in selecting an occlusal concept for patients with implants in the edentulous mandible. J Prosthet Dent 1995; 74:380-84.

22. Shaheen N. Effect of different occlusal schemes on the supporting structures of implant supported overdenture; MDS Ain Shams University. 2009; 78-82.

23. Matsumaru Y. Influence of mandibular residual ridge resorption on objective masticatory measures of lingualized and fully bilateral balanced denture articulation. J Prosthodont Res. 2010 Jul;54(3):112-8.

24. Niwatcharoenchaikul W, Tumrasvin W, Arksornnukit M. Effect of complete denture occlusal schemes on masticatory performance and maximum occlusal force. J Prosthet Dent. 2014;112:1337-42

25. Arksornnukit M, Phunthikaphadr T, Takahashi H. Pressure transmission and distribution under denture bases using denture teeth with different materials and cuspal angulations. J Prosthet Dent. 2011 Feb;105(2):127-36. 
26. Aarts JM, Payne AG, Thomson WM. Patients' evaluation of two occlusal schemes for implant overdentures. Clin Implant Dent Relat Res. 2008 Sep;10(3):140-56.

27. El Attar MS , Garrana HF. Effect of different occlusal schemes on the peri-implant tissues of implant supported prosthesis, Egypt. Dent. J. 1999; 45 (2): 4003-8.

28. Flanagan D. Rationale for Mini Dental Implant Treatment. J Oral Implantol. 2021 Oct 1;47(5):437-444.

29. Bural C, Geckili O, Erdogan O, Bektas-Kayhan K, Dayan SC. Reliability and validity of the Turkish version of oral health impact profile for edentulous subjects. Eur Oral Res. 2021 May 4;55(2):67-73.

30. Guo Y, Kono K, Suzuki Y, Ohkubo C, Zeng JY, Zhang $\mathrm{J}$. Influence of marginal bone resorption on two mini implant-retained mandibular overdenture: An in vitro study. J Adv Prosthodont. 2021 Feb;13(1):55-64.

31. Verma M, Nanda A, Sood A. Principles of occlusion in implant dentistry. J Int Clin Dent Res Organ 2015;7:27-33.

32. Chen YY, Kuan CL, Wang YB. Implant occlusion: Biomechanical considerations for implant supported prostheses. J Dent Sci 2008;3:65-74.

33. Sallam H, Kheiralla LS, Aldawakly A. Microstrains around standard and mini implants supporting different bridge designs. J Oral Implantol. 2012 Jun;38(3):221-229.

34. Naert I, Duyck J, Vandamme K. Occlusal overload and bone/ implant loss. Clin. Oral Implants Res. 2012; 23(Suppl. 6): 95-107.

35. Lazzara RJ, porter SS. Platform switching: a new concept in implant dentistry for controlling postrestorative crestal bone levels. Int $\mathrm{j}$ periodontics restorative dent. 2006; 26(1):9-17.

36. Enkling N, Moazzin R, Geers G, Kokoschka S, AbouAyash S, Schimmel M. Clinical outcomes and bone-level alterations around one-piece mini dental implants retaining mandibular overdentures: 5-year follow-up of a prospective cohort study. Clin Oral Impl Res. 2020; 31:549-556.

37. Misch CE. Dental Implant Prosthetics. 1st ed. . St. Louis: Mosby Elsevier; 2005.

38. Ismail HA, Yousief SA, Mahrous AI, Shaban AA, Azzeghaiby SN, Aljehani D. Clinical and Radiographic Evaluation of Median Lingualized Occlusion in Implant Retained Mandibular Complete Overdenture. J Int Oral Health. 2015;7(Suppl 1):5-8.

39. Wang Y, Bäumer D, Ozga AK, Körner G, Bäumer A. Patient satisfaction and oral health-related quality of life 10 years after implant placement. BMC Oral Health. 2021 Jan 14;21(1):30-7.

40. El Osta N, Haddad E, Fakhouri J, Saad R, El Osta L. Comparison of psychometric properties of GOHAI, OHIP-14, and OHIP-EDENT as measures of oral health in complete edentulous patients aged 60 years and more. Qual Life Res. 2021 Apr;30(4):1199-1213.

41. Park JH, Lee JY, Shin SW. Treatment Outcomes for Mandibular Mini-Implant-Retained Overdentures: A Systematic Review. Int J Prosthodont. 2017 May/June; 30(3):269-276.

42. Lemos CA, Verri FR, Batista VE, Júnior JF, Mello CC, Pellizzer EP. Complete overdentures retained by mini implants: A systematic review. J Dent. 2017 Feb; 57:4-13.

43. Ismail E, Assad A, Badawy M, Mohamed S. Comparison between monoplane occlusion and median lingualized occlusion in implant retained mandibular complete overdenture. Doctor Thesis. Faculty of Dental Medicine, Al-Azhar University, (Boys-Cairo) Removable Prosthodontics Department; 2010: 95-99.

44. Zarb GA, Bolender CL, Eckert SE, Jacob RF, Fenton AH, Mericske-Stern R. Prosthodontic treatment for edentulous patients-Complete Dentures and Implant-Supported Prostheses. 13th ed. . St. Louis: Mosby Elsevier; 2012. 